\title{
천변여과지 모형에서 여재모래의 폐색현상 실험연구 An Experimental Study on the Clogging of Sand Filter in a Model Filtration-Pond
}

\author{
정재민 · 김승현 ${ }^{\dagger}$ \\ Jae-Min Jeong $\cdot$ Seung-Hyun $\mathrm{Kim}^{\dagger}$ \\ 영남대학교 환경공학과 \\ Department of Environmental Engineering, Yeungnam University
}

(2013년 9월 2일 접수, 2013년 9월 25일 채택)

\begin{abstract}
A pilot-scale sand-box experiment was performed in order to investigate the effect of cross-flow velocity on the clogging of the filter sand in a model filtration pond. The clogging phenomenon was observed during the operation with the cross-flow varied in stages in a range of $0 \sim 40 \mathrm{~cm} / \mathrm{sec}$, and the experimental result was analyzed using a numerical code. Results showed that the crossflow velocity in this range had no influence on the development of clogging and that clogging occurred mostly on the filter-surface. It was found that while the production rate decreased from $5 \mathrm{~m}^{3} / \mathrm{m}^{2}$-day to $3 \mathrm{~m}^{3} / \mathrm{m}^{2}$-day the clogging coefficient of the top $50 \mathrm{~cm}$ layer increased up to about $30,000 \mathrm{sec}$, which corresponded to $87 \%$ of the clogging coefficient of the total $2.4 \mathrm{~m}$ layer. Of the clogging coefficient of the top $50 \mathrm{~cm}$ layer, surface clogging constituted $90 \%$ while the other $10 \%$ was intermediate clogging. It was also found that the surface clogging increased while the intermediate clogging remained constant as the operation continued, and that filtrate turbidity along the filtration depth remained constant in spite of the increase in clogging.
\end{abstract}

Key Words : Filtration Pond, Pilot-Scale, Sand-Box Experiment, Clogging Coefficient, Surface Clogging

요약 : 천변여과지에서 표류수 유속이 여재의 폐색에 주는 영향을 파악하기 위하여 파일럿 규모의 실험을 수행하였다. 표류 수 유속을 $0 \sim 40 \mathrm{~cm} / \mathrm{sec}$ 범위에서 단계적으로 변화시키면서 설비를 운전하여 폐색이 발달하는 현상을 관측하였고, 관측결과를 수치해석코드로 해석하여 폐색계수를 얻었다. 연구결과 이 범위의 표류수 유속에서는 표류수 유속이 폐색발달에 영향을 주 지 않는 것으로 나타났고, 폐색은 주로 표층에서 발생함을 알 수 있었다. 여과수 산출율이 $5 \mathrm{~m}^{3} / \mathrm{m}^{2}$-day에서 $3 \mathrm{~m}^{3} / \mathrm{m}^{2}$-day까지 감소하는 동안 표층 $50 \mathrm{~cm}$ 에서의 폐색계수는 약 $30,000 \mathrm{sec}$ 까지 증가하였으며, 이는 전체 여재두께 $2.4 \mathrm{~m}$ 가 가지는 폐색계수 의 $87 \%$ 에 해당되었다. 표층 $50 \mathrm{~cm}$ 의 폐색계수에서 표면폐색이 $90 \%$ 정도를 차지하여 내부폐색은 약 $10 \%$ 에 불과함을 알 수 있었다. 운전지속에 따라 표면폐색은 심화되었지만 내부폐색은 일정함도 알 수 있었다. 또한, 폐색이 진행되어도 여과깊이에 따른 탁도분포는 일정함을 알 수 있었다.

주제어 : 천변여과지, 파일럿 규모, 모래통 실험, 폐색계수, 표면폐색

\section{1. 서 론}

저농도로 오염된 다량의 하천수를 처리할 수 있는 보급 기술(Low-tech)로 다목적 천변여과지가 제안되어 연구되었 다. ${ }^{1)}$ 이 기술은 하천변의 저류지 내부에 격막을 설치하여 수 $\mathrm{km}$ 에 달하는 인공하천을 조성하고, 하천바닥에 약 $3 \mathrm{~m}$ 두께의 모래층을 설치하여 하상여과를 적용하는 방식으로, 복류수에서 부유물질, $\mathrm{BOD}$ 등이 잘 제거되는 특성을 활용 하는 방안이다. ${ }^{2)}$ 하상여과에서 하상의 단위면적당 여과수 산출율은 여재의 투수계수에 의해 크게 영향을 받지만, 천 변여과지에서는 좋은 여재를 택할 수 있어 그 투수계수는 여과수 산출율에 문제가 되지 않는다. 그러나 이 설비는 여 과수 산출율이 하상 $1 \mathrm{~m}^{2}$ 당 $3 \sim 5 \mathrm{~m}^{3} / \mathrm{day}$ 로 커서 하상의 폐 색이 빨리 진행되므로 폐색에 의한 하상의 투수계수 감소 가 산출율 감소의 큰 원인이 된다. 한편, 이 설비에서 인공 하천의 최상류에서는 유량이 백만 $\mathrm{m}^{3} / \mathrm{day}$ 정도로 크고 유 속도 크지만 하류로 갈수록 감소하여 최하류에서는 유량이 없는 부등정류이다. ${ }^{1)}$ 하천수가 하상면적 전체를 통하여 하
상으로 침투하기 때문이다. 일반적으로 강변여과에서 하상 의 폐색은 하천표류수의 유속과 상관이 있으므로 천변여과 지에서도 인공하천에서의 위치 즉, 표류수 유속에 따라 하 상의 폐색이 다르게 발달할 수 있다. ${ }^{3)}$ 또한, 천변여과지에 서는 폐색이 심화되면 이를 기계적으로 제거하므로 설비의 성공적인 설계와 운영을 위해서는 이 설비에서 가능한 다 양한 표류수 유속에서의 폐색발달과 또한 기계적 폐색제거 시 잔류하는 폐색정도 등을 파악할 필요가 있다.

폐색은 여과공정에 수반하는 현상으로 여과수 산출율에 큰 영향을 준다. 그러나 천변여과지와 유사하면서 오랜 역 사를 가진 강변여과에서도 여과수질에 관해서는 많은 연구 가 수행된 바 있지만, ${ }^{4)}$ 폐색에 관한 연구는 많지 않은 실정 이다. 강변여과에서 폐색과 산출유량 사이의 관계를 확인 한 최초의 사례로, 1954년 독일의 라인강변 Flehe의 강변여 과정 부근에서 하상의 폐색을 제거하자 산출유량이 크게 증 가했으나 2주 후 원래의 유량으로 감소하여 폐색의 중요성 을 인식했다 한다. ${ }^{5)}$ 이 조사에서 투수계수 약 $10^{-6} \mathrm{~cm} / \mathrm{sec}$, 두께 $2 \mathrm{~mm}$ 정도의 표면폐색이 관측되었고, 내부폐색은 하 
상에서 약 $10 \mathrm{~cm}$ 깊이까지만 관측되었다고 한다. 독일의 엘 베강변 드레스덴시 강변여과정에서도 1975년 하상의 폐색 을 조사한 바 있으며, 표면폐색은 관측되지 않았고, 두께 3 $10 \mathrm{~cm}$, 투수계수 $0.1 \sim 1.5 \times 10^{-5} \mathrm{~cm} / \mathrm{sec}$ 인 내부폐색만 관측 되었다고 한다. ${ }^{6}$ 한편, 강변여과에서 발생하는 폐색을 파악 하기 위한 칼럼실험도 수행된 바 있으며, Grischek과 Macheleidt는 엘베강의 강변여과를 모사하는 칼럼실험에서 표면 폐색은 없었고 대수층의 내부폐색이 $3 \mathrm{~cm}$ 깊이까지 발생하 였으며 이 층의 투수계수는 약 $6 \times 10^{-6} \mathrm{~cm} / \mathrm{sec}$ 였다고 한다. ${ }^{6}$ 이들의 실험에서 칼럼상부에 적용한 표류수 유속은 엘베강 의 평균유속인 $1 \mathrm{~m} / \mathrm{sec}$ 로 빠른 편이었다. 우리나라에서도 하상여과에서 폐색현상을 파악하기 위한 연구가 수행된 바 있으며, 낙동강 중류의 모래를 채운 칼럼에 하천수를 통과 시키는 실험결과 두께 $5 \mathrm{~mm}$, 투수계수 $6.1 \times 10^{-6} \mathrm{~cm} / \mathrm{sec}$ 인 표면폐색이 형성되었으며, 내부폐색은 약 $20 \mathrm{~cm}$ 깊이까지 형성되었고 깊이에 따라 폐색정도는 감소하였다고 한다. ${ }^{7)}$ 이들의 실험에서 표류수의 유속은 없었다. 이러한 연구들은 표류수 유속이 없거나 또는 매우 빠른 경우에 대한 것이어 서, $0 \sim 0.4 \mathrm{~m} / \mathrm{sec}$ 범위에서 연속적으로 변하는 천변여과지에 바로 적용하기에는 적합하지 않다고 할 것이다.

본 연구에서는 파일럿 규모의 천변여과지를 설치하여, 0 $0.4 \mathrm{~m} / \mathrm{sec}$ 범위의 표류수 유속으로 운영함으로써 표류수 유 속에 따라 하상의 폐색이 발달하는 정도를 파악하고, 기계 적으로 표면폐색을 제거한 후 잔류하는 내부폐색을 정량화 함으로써 천변여과지의 설계와 운영에 필요한 기초자료를 제공하고자 한다.

\section{2. 실험장치 및 방법}

천변여과지를 모사하는 실험장치로 길이 $5.5 \mathrm{~m}$, 폭 $1.5 \mathrm{~m}$, 높이 $3.0 \mathrm{~m}$ 인 철판으로 제작된 윗면이 없는 직육면체 유수 조를 제작하였다. 이 유수조를 수평으로 설치한 후 낙동강 의 칠곡군 석적읍에서 얻은 4대강사업 준설토를 $2.5 \mathrm{~m}$ 높이 까지 채웠다. 모래의 표면은 경사가 없었다. 사용된 모래의 투수계수는 $37 \mathrm{~m} / \mathrm{day}$, 유효입경은 $0.3 \mathrm{~mm}$ 그리고 균등계수 는 2.6이었다. 유수조의 하류에는 높이조절이 가능한 위어를 설치하여 표류수가 월류하도록 하였다. 유수조에 모래를 채 우기 전에 수평집수관을 설치하였으며, 이 집수관의 설치위 치는 유수조의 바닥면에서 $10 \mathrm{~cm}$, 그리고 한쪽 벽면에서 10 $\mathrm{cm}$ 만큼 떨어진 곳이 집수관의 중심이 되도록 하였고, 유수 조의 길이방향으로 하류의 $470 \mathrm{~cm}$ 구간에 설치하였다. 집 수관은 개공눈이 다수 뚫린 폴리에틸렌 파이프로 개공율은 $20 \%$, 내경은 $43.5 \mathrm{~mm}$ 였다.

유수조의 상류에 인접하여 길이 $0.5 \mathrm{~m}$, 폭 $1.5 \mathrm{~m}$, 높이 3 $\mathrm{m}$ 인 유입조를 설치하였다. 유수조의 하류에 인접하여 길이 $1.0 \mathrm{~m}$, 폭 $1.5 \mathrm{~m}$, 높이 $3.0 \mathrm{~m}$ 인 저류조를 설치하였으며, 이 는 유수조 하류에서 방류되는 표류수를 다시 상류로 양수하 여 순환시킴으로써 유수조에서 큰 유량을 얻기 위함이었다.

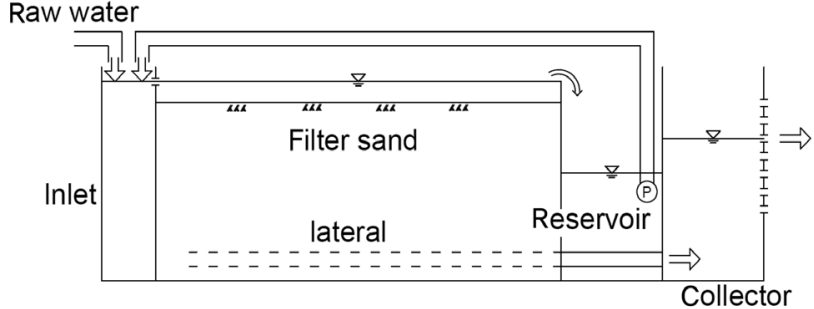

Fig. 1. Schematic diagram of the experimental apparatus.

저류조에 인접하여 집수조를 설치하였으며, 집수조의 규격 은 길이 $1.0 \mathrm{~m}$, 폭 $1.5 \mathrm{~m}$, 높이 $3.0 \mathrm{~m}$ 였다. 모든 설비는 철 판으로 제작되었고, 같은 수평면에 설치되었다. 수평집수관 의 저류조 통과구간은 집수관과 같은 규격의 무공관을 사 용하였으며, 수평집수관은 집수조에 연결되어 여과수가 집 수조로 유입되도록 하였다. 집수조 벽면에는 개폐식 밸브가 장착된 내경 $6.5 \mathrm{~cm}$ 의 원형 배수구를 7공 설치하였으며, 배수구의 중심의 위치는 집수조 바닥면으로부터 각각 2.50 $\mathrm{m}, 2.25 \mathrm{~m}, 2.00 \mathrm{~m}, 1.75 \mathrm{~m}, 1.50 \mathrm{~m}, 1.25 \mathrm{~m}, 1.00 \mathrm{~m}$ 였다. 실험장치의 개요도는 Fig. 1 에 나타내었다.

실험장치는 고령군 다산면 야외에 설치하였고, 낙동강물 을 실험에 사용하였다. 실험방법은 유입조에 강물과 저류 조에서 양수한 순환수를 공급하여 유수조에 일정한 표류수 유속이 발생하도록 하면서 집수조의 출구밸브를 열어 여과 수 산출율이 약 $5 \mathrm{~m}^{3} / \mathrm{m}^{2}$-day가 되도록 하여 운전을 시작하 였다. 운전으로 여재에 폐색이 발생하여 산출율이 약 $3 \mathrm{~m}^{3} /$ $\mathrm{m}^{2}$-day까지 감소하면 이를 1 주기로 보아 운전을 종료하고, 갈퀴로 표층을 교란하여 폐색을 제거하였다. 이 과정에서 운전주기를 늘이기 위해 집수조의 출구밸브를 낮추기도 하 였다. 적용된 표류수 유속은 $2 \mathrm{~cm} / \mathrm{sec}, 10 \mathrm{~cm} / \mathrm{sec}, 20 \mathrm{~cm} / \mathrm{sec}$, $30 \mathrm{~cm} / \mathrm{sec}$ 그리고 $40 \mathrm{~cm} / \mathrm{sec}$ 의 순서였고, 하나의 표류수 유 속에 대한 실험을 마친 후에는 순환수 양수율을 증가시킴 으로써 표류수 유속을 단계적으로 증가시키면서 동일한 실 험을 반복하였다. 이후 표류수의 유속이 없는 무유속 실험 도 추가하였으며, 이때는 유수조에 원수를 공급하여 여과수 로 빠져나가는 유량만큼만 보충하였다. 한편, 표류수 유속 $30 \mathrm{~cm} / \mathrm{sec}$ 에 대한 실험 전에 직경 $13 \mathrm{~mm}$ 인 자갈을 두께 3 $\mathrm{cm}$ 로 살포하여 유사이송을 방지하였다. 유수조의 중간부분 에 모래표면에서 $10 \mathrm{~cm}, 20 \mathrm{~cm}, 30 \mathrm{~cm}, 50 \mathrm{~cm}, 100 \mathrm{~cm}, 150$ $\mathrm{cm}, 200 \mathrm{~cm}$ 그리고 $240 \mathrm{~cm}$ 깊이에 내경 $2 \mathrm{~mm}$, 두께 $0.5 \mathrm{~mm}$ 인 비닐튜브로 시료채취구를 설치하였다. 운전기간 동안 표류수와 집수조의 수위, 산출유량 그리고 원수와 $240 \mathrm{~cm}$ 깊이의 시료에 대한 탁도는 매일 측정하였고, 각 표류수 유 속에서 산출율이 $5 \mathrm{~m}^{3} / \mathrm{m}^{2}$-day, $4 \mathrm{~m}^{3} / \mathrm{m}^{2}$-day, $3 \mathrm{~m}^{3} / \mathrm{m}^{2}$-day일 때에는 나머지 지점의 탁도도 관측하였다. 산출유량 측정 은 초시계와 매스실린더를 사용하였고, 탁도측정은 LP2000 (Hanna사, 이태리)을 이용하였다. 실험은 2012년 10월 1일 부터 2013년 5월 4일까지 동절기 약 2개월을 제외하고 수 행하였다. 


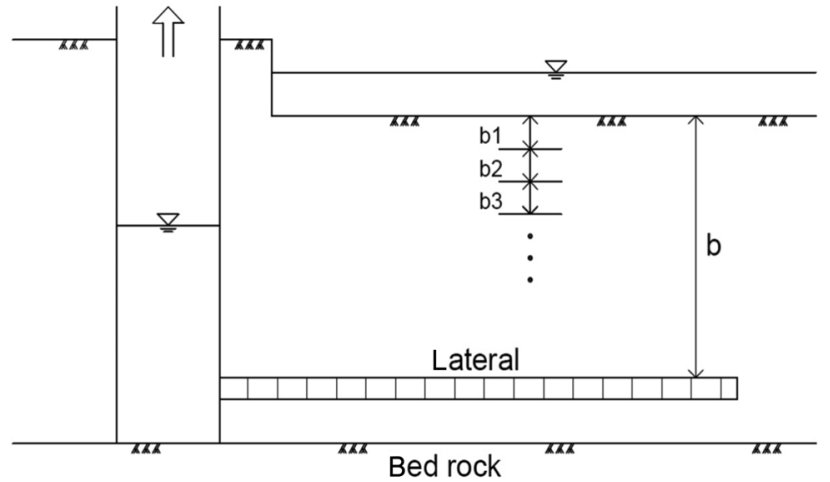

Fig. 2. Schematics of filtration pond with sand layers of different permeability.

\section{3. 폐색도 표현방식}

천변여과지와 유사한 강변여과에서 하상의 폐색을 표현하 는 방법은 크게 3 가지이다. 첫째는 누수도( $1 / \mathrm{day})$ 로, 투수량 계수를 함양유효거리의 제곱으로 나눈 값이다. ${ }^{3)}$ 둘째는 누 수계수 $(1 / \mathrm{sec})$ 로, 폐색층의 투수계수를 그 층의 두께로 나눈 값이며, 지하수 산업에서 널리 쓰인다. ${ }^{8)}$ 셋째는 폐색계수 $(\mathrm{sec})$ 로 누수계수의 역수이며 독일의 엘베강 강변여과의 평가를 위해 최초로 고안되었고, $w=\frac{b}{K}$ 로 표시하며, 여기서 $b$ 는 폐색층의 두께 $(\mathrm{cm}), K$ 는 폐색층의 투수계수 $(\mathrm{cm} / \mathrm{sec})$ 를 나타 낸다. ${ }^{6}$ 폐색계수는 대수층에서의 흐름에 대한 저항을 나타 내며, 하상여과나 천변여과지 등 수평집수관이 표류수의 하 방에 설치되는 경우에 활용하기 쉬운 특성을 가진다. Fig. 2 에는 천변여과지에서 폐색에 의해 형성되는 여러층을 나타 냈으며, 여과수 침투율을 계산하는데 필요한 평균투수계수는 $K_{a v e}=\frac{\sum b_{i}}{\frac{b_{1}}{K_{1}}+\frac{b_{2}}{K_{2}}+\cdots}$ 로 표시되고, ${ }^{8)}$ 여기서 분모의 각 항은 각 층의 폐색계수임을 알 수 있다. 따라서 폐색계수를 이용 하면 여과수 흐름에 대한 각 층의 저항을 정량적으로 파악 할 수 있고 또한, 이 과정에서 표층이나 내부층 하나하나의 폐색계수를 정확히 알지 못해도 몇 개 층의 평균 폐색계수 를 구하여 여과수 산출율을 정확히 예측할 수 있는 장점도 있어 본 연구에서는 이를 사용한다.

\section{4. 결과 및 고찰}

표류수 유속이 $2 \mathrm{~cm} / \mathrm{sec}$ 인 경우 유수조 운전에 따라 여과 수 산출율이 감소하는 현상을 Fig. 3에 나타냈다. 이 실험 에서 유수조의 표류수 수심은 $10 \mathrm{~cm}$ 였고, 표류수와 집수조 의 수위차는 $85 \mathrm{~cm}$ 였다. 여과수 산출율은 선형으로 감소함 을 알 수 있으며, 이는 다른 표류수 유속에서도 마찬가지였 다. 이와 같은 선형의 산출율 감소는 여재층에서 탁질이 점

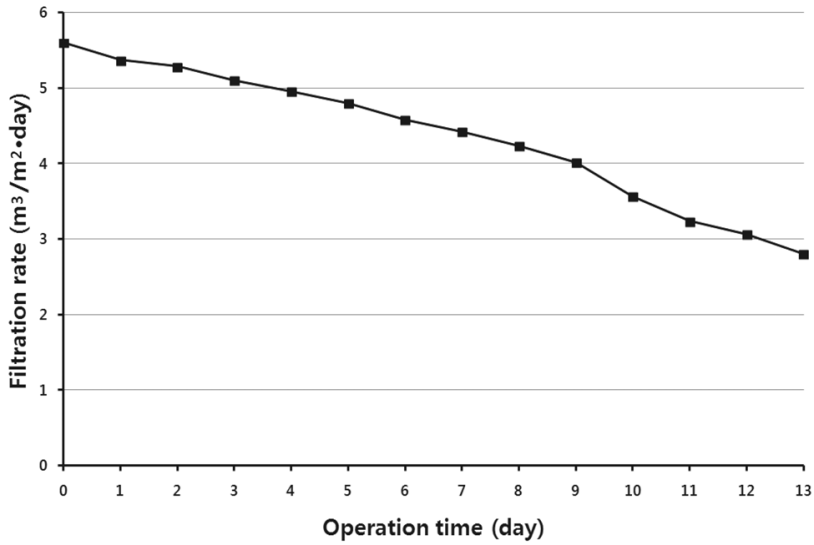

Fig. 3. Daily change in filtration rate (cross-flow velocity of $2 \mathrm{~cm} /$ sec).

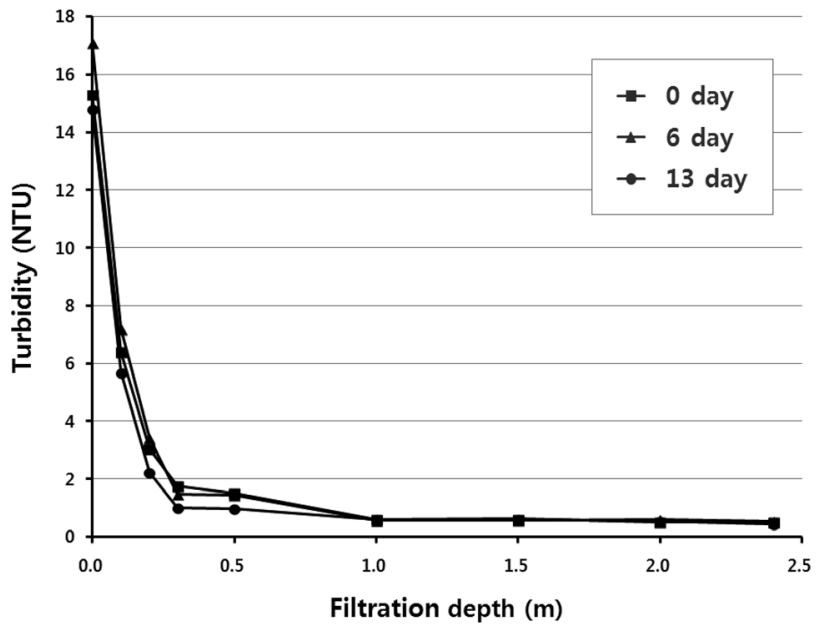

Fig. 4. Turbidity of filtrate along the filtration depth and operation time (cross-flow velocity of $2 \mathrm{~cm} / \mathrm{sec}$ ).

차 축적되는 폐색현상에 기인하는 것으로 판단되었다.

여재에서의 탁질축적을 확인하기 위하여, 표류수 유속 2 $\mathrm{cm} / \mathrm{sec}$ 의 운전에서 운전시간과 여과깊이별 탁도 관측치를 Fig. 4에 나타내었다. 대부분의 탁도가 $50 \mathrm{~cm}$ 이내의 표층 에서 제거되었고, 운전지속으로 폐색이 심화되어도 여과깊 이에 따른 여과수의 탁도분포는 거의 일정한 양상을 보였으 며, 이는 다른 표류수 유속에서도 공통적인 현상이었다. 표 층에서의 지속적인 탁도제거는 제거된 탁질의 축적으로 인 한 표층의 폐색을 일으킬 것이므로, Fig. 4는 강변여과나 하 상여과 그리고 완속여과 등에서 주로 표층에 폐색이 형성된 다는 보고와 부합한다고 볼 수 있다. ${ }^{5,7,9}$

Fig. 3에 나타낸 산출율과 운전기간 중 매일매일의 표류 수와 집수조의 수위로부터 표층의 폐색계수를 계산하여 Fig. 5에 나타내었고, 여기에는 다른 표류수 유속에서의 계 산결과도 함께 나타내었다. 표층의 폐색계수를 결정한 방법 은 지하수 수치해석코드인 MODFLOW에 유수조의 운전조 건을 입력하고 여재의 최상층 투수계수로 다양한 값을 입력 하면서 여과수 산출율을 가장 잘 예측하는 투수계수를 택하 여 이를 폐색계수로 환산하였다. ${ }^{10)}$ 이때 적용한 블록의 크 


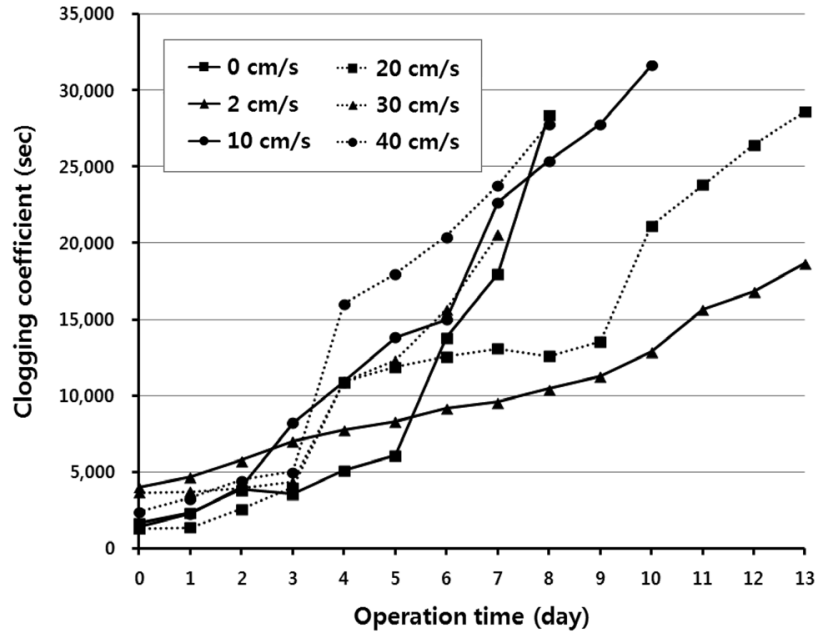

Fig. 5. Daily change in clogging coefficient of surface layer according to the operation time and cross-flow velocities.

기는 각 변의 크기가 $50 \mathrm{~cm}$ 인 정육면체였다. 모든 표류수 유 속에서 운전이 진행됨에 따라 표층 $50 \mathrm{~cm}$ 의 폐색계수도 증 가하여 여과수 산출율이 $3 \mathrm{~m}^{3} / \mathrm{m}^{2}$-day까지 감소했을 때 최대 약 $30,000 \mathrm{sec}$ 에 달했으며, 이는 보통의 강변여과에서 적용하 는 $100,000 \mathrm{sec}$ 보다 횔씬 작은 값이었다.) 또한, 표류수 유속 은 폐색의 발달에 영향을 주지 않은 것으로 나타났으며, 이 는 표층에 폐색층이 형성되는 과정에서 여과수의 침투로 인 한 하향압력으로 폐색물질이 치밀하게 조직되었고, $40 \mathrm{~cm} / \mathrm{sec}$ 까지의 표류수 유속에 의한 소류력이 이를 제거하기에는 부 족하였기 때문으로 판단되었다. 폐색계수가 $30,000 \mathrm{sec}$ 일 때 표층 $50 \mathrm{~cm}$ 에서의 저항이 여재층 전체의 저항에서 차지하 는 비율을 구했으며, $87 \%$ 에 달하였다. 표층을 제외한 나머 지 $190 \mathrm{~cm}$ 구간에서의 폐색계수가 $\frac{1.9 \mathrm{~m}}{37 \mathrm{~m} / \mathrm{day}} \times 4,437 \mathrm{sec}$ 에 불과하기 때문이다. 모래여과에서 표층폐색은 다시 표면 폐색과 내부폐색으로 구분할 수 있으며, 표면폐색은 모래 표면에 수 $\mathrm{mm}$ 정도의 두께로 발달하고, 내부폐색은 모래표 면에서 최대 약 $20 \mathrm{~cm}$ 깊이까지 발달하며, 폐색물질은 오염 물과 이를 분해하는 미생물로 구성되는 것으로 알려져 있 다. ${ }^{5,79)}$ Fig. 5 에서 각 표류수 유속에 대한 운전초기의 폐색 계수 1,267 4,034 sec는 표면폐색을 제거한 직후 얻었으므로 내부폐색으로 볼 수 있다. 이 값들은 유수조를 운영하기 전 순수한 모래층 $50 \mathrm{~cm}$ 의 폐색계수 $\frac{0.5 \mathrm{~m}}{37 \mathrm{~m} / \mathrm{day}} \times 1,168 \mathrm{sec}$ 와 큰 차이가 없으며, 폐색이 발달했을 때인 약 $30,000 \mathrm{sec}$ 의 4 13\%에 불과하여, 표면폐색이 차지하는 $87 \sim 96 \%$ 에 비해 내 부폐색은 산출율 감소의 주원인이 아님을 나타내고 있다. 또한, 표면폐색과 달리 내부폐색은 운전이 지속되어도 심화 되는 경향을 보이지 않음을 알 수 있었다. 본 연구에서 내 부폐색계수의 범위가 다소 큰 것은 표면폐색 제거시 인력 을 사용하여 균일한 제거가 이루어지지 않았고 내부폐색의 일부가 함께 제거되었기 때문으로 판단되었다.

표류수 유속 $2 \mathrm{~cm} / \mathrm{sec}$ 의 운전에서 여재에 축적된 탁도와

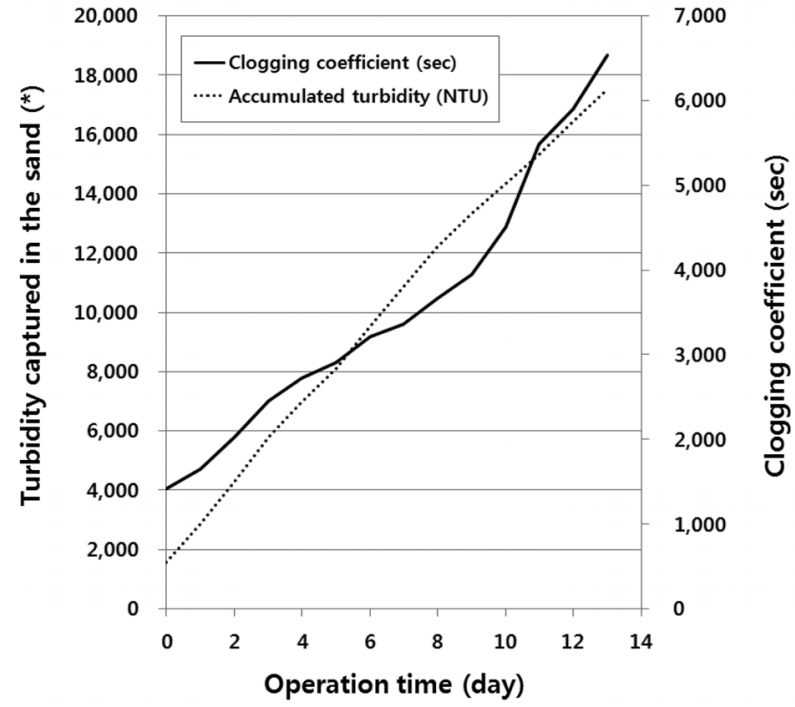

Fig. 6. Change with operation time in clogging coefficient and turbidity captured in the sand (cross-flow velocity of 2 $\mathrm{cm} / \mathrm{sec}$ ).

폐색계수의 관계를 Fig. 6에 나타내었다. 여기서 축적된 탁 도는 (제거된 탁도) $\times$ (통과유량)을 나타낸다. 폐색계수의 증 가 즉, 폐색의 발달은 탁도의 축적에 비례함을 알 수 있었 고, 이 현상은 다른 표류수 유속에서도 공통적으로 관측되 었다.

\section{4. 결 론}

모래여과에서 표류수 유속 $40 \mathrm{~cm} / \mathrm{sec}$ 이하에서는 폐색에 대한 표류수 유속의 영향이 없는 것으로 나타났으며, 폐색 은 표층에서 주로 발생함을 알 수 있었다. 여과수 산출율이 $5 \mathrm{~m}^{3} / \mathrm{m}^{2}$-day에서 $3 \mathrm{~m}^{3} / \mathrm{m}^{2}$-day까지 감소하는 동안 표층 50 $\mathrm{cm}$ 에서의 폐색계수는 약 $30,000 \mathrm{sec}$ 까지 증가하였으며, 이 값은 전체 여재두께가 가지는 폐색계수의 $87 \%$ 에 달했다. 또 한, 표층 $50 \mathrm{~cm}$ 의 폐색계수 중에서도 표면폐색이 약 $90 \%$ 를 차지하여 $10 \%$ 정도에 불과한 내부폐색에 비해 횔씬 컸 고, 내부폐색은 운전이 지속되어도 심화되지 않음을 알 수 있었다. 폐색이 심화되어도 여과깊이에 따른 탁도분포는 일 정함을 알 수 있었다.

KSEE

\section{참고문헌}

1. Sohn, D.-H., Park, J.-Y. and Kim, S.-H., "A Study on the Design of Artificial Stream for Riverbed Filtration in Multipurpose Filtration Pond," J. Kor. Soc. Environ. Eng., 33(7), 536 543(2011).

2. Baik, M. Y., "A study on purifying efficiency of water quality analysis for infiltrated water as filtered distance-focu- 
sing on Purification Plant at Goryeong, Gyeongbuk," Graduate School of Environmental Study, Yeungnam University, Korea(2012).

3. Hubbs, S., Ball, K., Haas, D. and Robison, M., "Chap. 4. Riverbank filtration construction options considered at Louisville, Kentucky," in Riverbank filtration-Improving sourcewater quality, edited by Ray, C., Melin, G. and Linsky R. B., Kluwer Academic Publishers(2002).

4. Ray, C., Melin, G. and Linsky R. B.(ed.), "Riverbank filtration-Improving source-water quality," Kluwer Academic Publishers(2002).

5. Schubert, J., "Chap. 3. German experience with riverbank filtration systems," in "Riverbank Filtration-Improving sourcewater quality," edited by Ray, C., Melin, G., and Linsky, R. B., Kluwer Academic Publishers, pp. 35 48(2002).

6. Grischek, T. and Macheleidt, W., "Investigations into riverbed clogging at RBF sites along the Elbe River, Ger- many," $2^{\text {nd }}$ International Workshop on Riverbank/Riverbed Filtration, International Collaboration Center, KIST, May $9^{\text {th }}$. $11^{\text {th }}(2006)$.

7. Kim, S.-H., Sohn, D.-B. and Ahn, K.-H., "A Study on the Reduction of Hydraulic Conductivity in a Model System of Riverbed Filtration,” J. Kor. Soc. Environ. Eng., 25(4B), 301 308(2005).

8. Fetter, C. W., “Applied Hydrogeology,” Macmillan College Publishing Company, Inc., New York(1994).

9. Unger, M., "The role of the schmutzdecke in E. coli removal in slow sand and riverbank filtration," Master's thesis, University of New Hampshire, U.S.A(2006).

10. Harbaugh, A. W. and McDonald, M. G., "User's documentation for MODFLOW-96. An update to the U.S. Geological Survey Modular Finite-Difference Ground-Water Flow Model," Open File Report 96-485, U.S. Geological Survey, Reston, Virginia, U.S.A(1996). 